\title{
Theological Compatibilism and Essential Properties
}

\author{
Nicola Ciprotti \\ Universität Salzburg
}

I first met Flavio Baroncelli in the annual meeting of Italian graduate students held in Reggio Emilia in late 2003. My talk was on free will and determinism. He pressed me with keen questions and remarks. Later on, through mail exchanges I found him to be a vigorous incompatibilist, both causal and theological: he unhesitatingly aligned with those theorists who believe free will to count inconsistent with causal determinism, on one side of the dispute, and with God's infallible foreknowledge, on the other side. My present tribute to him consists in tackling and (hopefully soundly) rebutting one of the most prominent defences of theological compatibilism currently on offer. For, even if I am no more confident that compatibilism over both issues is in principle untenable, I do think that the account to follows is.

0. Alvin Plantinga defends Theological Compatibilism (TC) and Essentialism about property possession (E). TC is the claim that human freedom to act otherwise and God's essential omniscience are compatible, while $\mathrm{E}$ is the claim that every individual entity whatsoever has a modal profile consisting in having both essential and accidental properties. I purport to show that, if $\mathrm{E}$ is assumed in the argument for TC, then the latter leads to a very puzzling upshot. I also intend to show that, even if TC is suitably fixed in order to avoid that upshot, $\mathrm{TC}$ is still unconvincing in that it merges into one the de re and the de dicto rendering of 'human freedom to act otherwise'; I end up by briefly sketching why the two renderings should instead be kept well apart.

1. TC is the claim that God's essential omniscience and creaturely libertarian freedom conceived as power to do otherwise are compatible. That is, TC holds that human agents are free to act otherwise even though God is omniscient at every possible world.

In order to grasp what is at stake in TC we need to follow Plantinga's definitions for our key terms, viz. 'essential omniscience' and 'libertarian freedom'. As to the former, according to Plantinga, where ' $p$ ' varies over propositions,

(0) God is omniscient $=_{d f} \forall p(p \equiv$ God knows that $p)$;

whence

(1) God is essentially omniscient $=_{d f} \square \forall p(p \equiv \text { God knows that } p)^{1}$.

\footnotetext{
${ }^{1}$ Plantinga 1974b: 67-68. Notice that the above definition is not free from complications; as a matter of fact, it is controversial that in (1) ' $\square$ ' must read alethically, that is, as the operator for metaphysical necessity, unless it is assumed that the logic of divine knowledge is reducible to the logic of metaphysical modality.
} 
According to (0), God is omniscient iff she knows the truth-value of any proposition whatsoever; according to (1), God is essentially omniscient iff God is omniscient at all possible worlds in which she exists; and since God is taken to have necessary existence, (1) states that God is omniscient at every possible world whatsoever.

As is usually the case within the debate concerning human freedom and divine foreknowledge, moreover, 'God' is taken by Plantinga to be a proper name. This means that 'God' is regarded as rigidly denoting across worlds: for any world $w$, if 'God' denotes $a$ at $w$ (for ' $a$ ' individual constant) then 'God' denotes $a$ at every different world (notice that, since 'God' cannot fail denoting - she necessarily exists - so will ' $a$ '). Furthermore, God is also taken to be essentially sempiternal: necessarily, her existence is indefinitely extended both backward and forward in time ${ }^{2}$. Thus, for every world $w$, God is also taken to exist in every instant of time at $w$.

As to freedom as power to do otherwise (henceforth PDO) Plantinga reads it as follows:

(2) For any agent $x$ and contingent proposition $p, x$ has PDO at @ with respect to $p$ only if there is a world $w$ such that (i) $w$ is accessible to @, (ii) $x$ exists at $w$, (iii) $x$ makes it the case that $\sim p$ at $w^{3}$.

Now the question is: How is it possible that agents act otherwise given that God knows in advance how they will act? How is it possible to deceive a being who, qua essentially omniscient, is also infallible?

For it seems that, if God is essentially omniscient then God is also an infallible foreknower - she cannot be mistaken about the truth-value of any futuretensed proposition ${ }^{4}$. But if God infallibly foreknows that $x$ will make it the case that $p$ - say, at time $t$ - then $x$ cannot refrain at $t$ from making it the case that $p$, otherwise God would not be an infallible foreknower. But if it is not possible that something happens that God does not know, how can agents be free to act otherwise? As Plantinga puts it:

\footnotetext{
${ }^{2}$ We do not want to mean that divine timelessness is incoherent; it is only that existence outside of time seems to provide an easier way out of the dilemma of freedom and divine omniscience: God never foresees anything in that so-called future contingents are always present to her mind - just like my laptop keyboard is present to my vision at the moment I am typing these words. This solution to the dilemma is the one famously endorsed, for instance, by Boethius and Aquinas. For the current debate over God\&Time see for instance (but only for instance: the debate is gigantic) Pike 1970, Kenny 1979, Stump-Kretzmann 1981, Grim 1985, Helm 1988, Leftow 1991, Padgett 1992, Prior 2003. An excellent aerial view is provided in Fischer 1993; for a historical survey through medieval leading philosophers see Hughes 1995.

${ }^{3}$ Plantinga 1974b: 70. The 'Only if' proviso is because I take Plantinga to assume that $p$ 's being broadly logically possible is necessary for $p$ 's being ever freely brought about, though it might be not sufficient. As a result, (2) should not be taken as an explicit definition of 'PDO'. This very point is stressed by Phil Quinn in Quinn 1985: 275.

${ }^{4} \mathrm{By}$ that, it is not here implied the truth of Presentism, that is, the reality of tense; the locution in the text is to be interpreted thus: if God knows at $t_{1}$ that $p$ at $t_{2}$, then it is just that $t_{1}<t_{2}$, be the passage of time real or not: if the former, then $t_{2}$ has the property of futureness with respect to $t_{1}$; if the latter, then $t_{2}$ is just later than $t_{1}$.
} 
If God knows in advance that Paul will have an orange for lunch tomorrow, then it must be the case that Paul will have an orange tomorrow; and if must be the case that Paul will have an orange tomorrow, then it isn't possible that Paul will refrain from so doing - in which case he won't be free to refrain, and hence won't be free with respect to the action of taking an orange . $^{5}$.

2. This is the so-called dilemma of human freedom and divine foreknowledge, according to which, on the assumption of divine essential omniscience, there is a prima facie strong case against PDO. The argument against their consistency runs as follows.

Suppose that at $t_{1}$ God knows that $x$ will make it the case that $p$ at $t_{2}$ $\left(t_{1}<t_{2}\right)$. Suppose further that $t_{1}$ is many thousand years before $x$ 's birth. It follows that, were $x$ to act otherwise at $t_{2}$, then either (i) $x$ would make it the case that God had a false belief at $t_{1}$, or (ii) $x$ would make it the case that God had a different belief at $t_{1}$. However, (i) is impossible because God is essentially omniscient and infallible so that she can never be either ignorant or mistaken about any proposition; (ii) is impossible too because, since $t_{1}$ is past with respect to $t_{2}$ and since the past is unchangeable: no human being has power over events already come to pass, it follows that $x$ cannot make it the case at $t_{2}$ that God had a different belief at $t_{1}$. Hence, $x$ has no power over $p$ at $t_{2}$ either $^{6}$. According to this argument, therefore, God's essential omniscience and PDO are incompatible.

How (if ever) might the two be reconciled? Plantinga answers thus ${ }^{7}$.

(TC) Suppose that God knows in @ at $t_{1}$ that $x$ will make it the case in @ that $p$ at $t_{2}$. God's foreknowledge about $x$ 's acting at $t_{2}$ does not rule out $x$ 's PDO at $t_{2}$ because, if at $t_{2} x$ made it the case that $\sim p$, then there would be a world $w$ such that God in $w$ would believe at $t_{1}$ that $x$ would make it the case in $w$ that $\sim p$ at $t_{2}$; and since there is no possible world $w^{*}$ more similar to@ than $w$ such that in $w^{*}$ (i) $x$ makes it the case that $\sim p$, (ii) God does not believe that $x$ makes it the case that $\sim p$, it follows that God's actual infallible knowledge that $x$ makes it the case that $p$ at $t_{2}$ does not tell against $x$ 's PDO with respect to $p^{8}$.

Hence compatibilism is vindicated by means of showing that God's essential omniscience and PDO are merely covariant, so that $x$ is in fact endowed with a counterfactual PDO at $t_{2}$ (henceforth CPDO). As it happens, CPDO does not entail the power either to change God's beliefs or make God err about $x$ 's action at $t_{2}$. Thus God will never be in a position such that there is a world $w$ at which either she entertains a false belief or her belief is retro-caused by future creaturely actions. For, according to TC, what is only required for $x$ to have PDO with respect to $p$ is the truth of the following counterfactual:

\footnotetext{
${ }^{5}$ Plantinga 1974b: 66, original emphasis.

${ }^{6}$ For such an incompatibilist argument see Pike 1966, Fischer 1989.

${ }^{7}$ Plantinga 1974b: 70-73.

${ }^{8}$ Similarity among worlds is intended thus: $w_{i}$ is more similar to $w_{j}$ than $w_{k}$ only if (i) $w_{i}, w_{j}, w_{k}$ share the same initial segment, (ii) $w_{i}$ coincides with $w_{j}$ over the truth-value of a greater number of propositions than does $w_{k}$.
} 
(C) If at $t_{2} x$ made the case that $\sim p$, then at $t_{1}$ God would believe that $x$ makes it the case at $t_{2}$ that $\sim p$.

Since (C) is clearly true in that it just follows from the definition of 'essential omniscience' provided above and conditional logic, we ought to conclude that PDO and God's essential omniscience are compatible ${ }^{9}$.

3. However, even assuming for the sake of argument that CPDO is equivalent in content to PDO (what is debatable) TC is nevertheless troublesome when paired with E. Prior to seeing why, a little detour in Plantinga's modal metaphysics is needed. Suppose indeed that ' $x$ ' is a place holder for an individual of @, say, Jonah Lomu. What does it mean, then, that Jonah Lomu makes it the case that $\sim p$ at $w$ ? Is Jonah Lomu in the flesh to act otherwise at $w$, or is instead some among his counterparts?

It is likely that different answers will be prompted depending on which view of possible worlds one is committed to. So, were one to stick to Counterpart Theory, then she will answer that it is Lomu's $w$-counterpart to act otherwise at $w$, and not Lomu himself. Sure, maybe a counterpart very much resembling to "our" Lomu (for instance as fast, as muscular and as powerful in rugby as he) yet a different individual. On the other hand, should one advocate genuine transworld identity, as according to the many versions of Actualism, then she will be expected to maintain that, were $w$ actual, it would be the real Lomu (who else?) to act otherwise at $w$.

Plantinga advocates in fact genuine transworld identity. Therefore, TC seems grounded upon the conviction that it is $x$ at $w-x$ herself - to act otherwise, not anyone else. For, according to Plantinga, $w$ just plays the role of the alternative state of affairs in which $x$ does something different, other things being equal. So why should $x$ be a different individual at $w$ ?

In point of fact, it is plausible to assume, following Plantinga, that for any two individuals $x$ and $y$ and world $w_{i}$ and $w_{k}, x$ and $y$ are different across $w_{i}$ and $w_{k}$ only if $x$ and $y$ differ over their respective essential properties, whereas, for any property $\mathrm{P}$ and object $z, \mathrm{P}$ is essential to $z$ iff $z$ has $\mathrm{P}$ at every world at which $z$ exists $^{10}$. Since in TC there is no clue that $x$ 's acting otherwise at $t_{2}$ makes herself essentially different from the individual she is in @, we must conclude that $x$ 's identity across different worlds is not in trouble: it is $x$ in flesh and blood to act otherwise just because essential properties do match across such worlds.

3. I wish to show that it is the very distinction endorsed by Plantinga between essential and accidental properties, viz. E, to lead TC into troubles.

\footnotetext{
${ }^{9}$ Where ' $>$ ' stands for the counterfactual conditional, TC relies on the following inference: $\square(p \equiv q) \supset \sim q>\sim p$.

${ }^{10}$ As opposed to any property $\mathrm{P}^{*}$ possessed by $z$ at each world $w_{n-1}$ at which $z$ exists, viz. an accidental property of $z$ : see Plantinga 1974a: chaps. 4 and 5 . Since the question whether there exist non-existence-entailing properties, e.g. nonexistence, is quite awkward, let's assume, if only for the sake of argument, the truth of Serious Actualism: for any object $z$ and property $\mathrm{P}$, it is not possible for $z$ to have $\mathrm{P}$ without existing.
} 
To begin with, suppose that $x$ has $\mathrm{PDO}$ at $t_{2}$ with respect to $p$ at @. Indeed, TC just shows how and why she has. Since Plantinga seems ready to accept that PDO might be a property of individuals, it is sensible to suppose that he also takes PDO to be a non-trivial property of individuals. According to him, a property $\mathrm{P}$ is trivial iff it constitutes a necessary condition for some thing to exist, e.g. being self-identical, being $\mathrm{P}$ or not-P, and the like ${ }^{11}$. To the contrary, PDO does not seem so: for $x$ to exist it is not required that $x$ be free. Assume therefore that PDO is a non-trivial property of $x$. Now ask: Is it contingently the case that $x$ is free at $t_{2}$ to do otherwise? That is: Is PDO an accidental property of $x$ ? So far we are supposing it is non-trivial. Now we're asking whether PDO is an essential or accidental property of human agents. Well, either PDO is accidental, or it is not. If the former, then there is a world $w$ such that (i) $x$ exists at $w$, (ii) $x$ is not free at $t_{2}$ with respect to $p$ at $w$. But such a $w$ cannot exist in fact. For, either $w$ belongs to the class of accessible-to-@ worlds or it does not; if the former, then $w$ is by default such that if $x$ acted otherwise therein, then God would have a different belief at $w$; hence, to the extent that Plantinga does not provide us with reasons to the contrary, $w$ is to count as a world where $x$ acts otherwise. But this contradicts the hypothesis that $x$ is not free at $t_{2}$ with respect to $p$ in $w$. If the latter, it is not legitimate in the first place to count $w$ as an "eligible" world, that is, such that it is permitted to assess $x$ 's PDO with respect to it; but in this case as well Plantinga will have to supply non- $a d$ hoc reasons why $x$ is denied access to $w$. As a matter of fact, if $x$ is denied access to $w$ for ad hoc reasons, viz. independent on God's essential omniscience, then $w$ cannot be included from the outset in the class of possible worlds in respect to which we can sensibly ask whether $x$ has PDO over $p$ given God's essential omniscience: $w$ might be, for instance, a world such that $x$ could not make it the case that $\sim p$ even assuming that God not existed at $w^{12}$. In such a case, then, the existence of $w$ would be flat out immaterial to $x$ 's PDO; in other words, $w$ is not a world such that $x$ hasn't PDO with respect to $p$ given God's essential omniscience, but rather a world such that $x$ hasn't PDO with respect to $p$ for quite different reasons. Either case, $w$ cannot exist; hence, PDO cannot be contingently possessed by any human agent.

To take stock. We started from the supposition that PDO is an accidental property of $x$, to wit, that there is a world $w$ such that, even otherwise granting PDO to $x, x$ hasn't PDO with respect to $p$ in $w$; but from such a supposition we drew to the conclusion that $w$ cannot exist: reductio. Therefore, if the existence of $w$ is a necessary condition for PDO's being an accidental property of $x$, but $w$ does not exist, it follows it cannot be the case that PDO is an accidental property of $x$; hence we must conclude that - since according to Plantinga, for any $z$ and $\mathrm{P}$, if $z$ possesses $\mathrm{P}$ non-accidentally, it must be that $z$ possesses $\mathrm{P}$ essentially - the property 'PDO with respect to a proposition $p$ given God's essential omniscience' is essential to $x$. By definition of 'essential property', this

\footnotetext{
${ }^{11}$ Plantinga 1974a: 60-61.

${ }^{12}$ Example: suppose that @ is deterministic and that $x$ makes it the case that $p$ at @; then it seems there is no world $w$ such that $w$ has the same past and laws as @, yet $x$ makes it the case that $\sim p$ at $w$.
} 
means in turn that there is no world $w$ such that God is omniscient at $w, x$ exists at $w$ yet $x$ hasn't PDO at $w$. However, if it is not possible that $x$ fail to be free - it is not possible that $x$ have PDO at no world where $x$ exists - then, by the interdefinability of modal operators, it is necessary that $x$ has PDO given God's essential omniscience.

However, that for any human agent $x$ whatsoever it is necessary that $x$ has PDO, if ever does, is quite striking an upshot, to say the least. For it commits to holding that (i) if $\mathrm{TC}$ is sound and (ii) the distinction between essential and accidental properties as conceived of by Plantinga is correct, then (iii): if it is possible that an agent has PDO given God's essential omniscience, then it is necessary that such an agent has PDO. Hence it seems that Plantinga is trying to convince us that if it is possibly the case that $q$, then it is necessarily the case that $q$. Such a conclusion, though, is notoriously fallacious.

4. On behalf of Plantinga, two different counters might be raised. The first is as follows. That TC does lead to concluding that PDO is an essential property of any creaturely agent whatsoever carries no fallacy and thus it does not put an end on it; for, either the argument against TC (henceforth ATC) is valid, either it is not. If ATC is valid, then what it only succeeded in showing is that it is the very distinction between accidental and essential properties to lead in fact to the conclusion 'If $q$ is possible then $q$ is necessary'. Yet, upon granting the distinction, it seems that ATC goes validly through, so that it cannot be fallacious. But if ATC is not fallacious, neither TC is, since TC appeals to just the same premises as ATC. Thus, however one should assess the move from possibly $q$ to necessarily $q$, if ATC is valid, so must be TC. On the other hand, if ATC is invalid in that it relies on a modal fallacy, then TC will obviously end up unscathed. In either case, there is no sound argument against TC.

ATC can, however, successfully cope with the above counter; as it happens, ATC has a modus tollens form. If, as it stands, TC is conducive to the fallacy, then there is something wrong with TC. In other words, it seems that we have no need to show that the modal fallacy is not really such; we can grant instead it is ever fallacious to derive a necessary conclusion from a set of merely possible premises, and thereby focus our attention to the very premises. Since, therefore, the conclusion is modally fallacious, by modus tollens we must conclude that what is wrong with $\mathrm{TC}$ is either its implicit endorsement of $\mathrm{E}$, or the claim that PDO is a genuine property of creaturely agents. To put it differently. The ATC-ist can claim that, even if TC is by itself valid, it is not so as long as it is paired with $\mathrm{E}$, because the latter compels the TC-ist to take PDO either as an accidental or as an essential property (and nothing else, since the dichotomy essential/accidental is exhaustive of the logical space). Since ATC shows that PDO cannot be accidental, the TC-ist is bound to regard PDO as essential. But this move is deadly to TC, since it forces to the conclusion that the mere possibility of something being-such-and-so commits to its flat out necessity. Therefore, the ATC-ist can reply that (i) TC + E commits the TC-ist to taking side over whether PDO is essential or accidental; (ii) $\mathrm{TC}+\mathrm{E}$ cannot avoid taking PDO as essential; (iii) taking PDO as essential leads to moving from the 
mere possibility of PDO to its necessity. In order to avoid (iii), therefore, TC must break free of $\mathrm{E}$.

But what if PDO is a not a property in the first place? For, if it isn't, TC does not inherit any modal fallacy. So the second counter on behalf of Plantinga is that TC should not read as a de re claim about human agents, but merely as a de dicto one about the logical consistency of God's essential omniscience and PDO; in such a case ATC's reductio would simply be a non-starter. In other words, Plantinga could retort that he only purported to show that it is in fact logically possible that $x$ 's PDO and divine essential omniscience coexist in the same world; not that, given divine essential omniscience, human agents have not the property of PDO. True, in the latter case - the de re one - PDO would in fact count as a genuine property of creaturely agents; yet - so could he reply - TC is only concerned with the former, de dicto, case, whose only aim is to prove the existence of a possible world such that a given agent $x$ does act otherwise therein even upon assuming God's essential omniscience. In sum, TC could be quite legitimately regarded as a claim about possible worlds and the nature of modal space under the joint assumption of PDO and divine essential omniscience; but not as a claim about this-worldly human powers and abilities. And in this case it would be utterly clear that PDO shouldn't be counted as a property of agents, either accidental or essential, so that TC couldn't be charged at all with any modal fallacy such as the one just considered.

In spite of this, I still believe this last-ditch rejoinder to be ineffective. In the first place, Plantinga does speak as if what is really at stake in the dispute is a substantive property like PDO: Could human agents be such-and-so if God is such-and-so? When talking of 'being free with respect to an action', he explicitly refers to the usual libertarian conception of freedom, according to which agents are free iff they have the power both to bring about \& to refrain from a given course of action ${ }^{13}$. Granted, maybe he takes freedom simply to consist in the existence of a class of possible worlds such that, were one of them actual, $x$ would act otherwise therein. In such a case, therefore, the de re claim would actually and successfully reduce to the de dicto one. However, this move would commit Plantinga to maintaining that creaturely agents have PDO only provided there is a possible world, far though it may be from actuality, where the same individual exists and acts otherwise. In other words, he would be assenting to the conviction that the mere existence of (and accessibility to) such a world is sufficient for PDO. But this is implausible (see footnote 3) for this would not be freedom as humanly power to act otherwise but something very close to omnipotence. In point of fact it is pretty clear that, if an agent $x$ has $\mathrm{PDO}$ with respect to an action-type $\mathrm{A}$ iff there is an accessible world where $x$ exists and successfully performs an A-type action-token, this definition of PDO is likely to lead to an "oversized" kind of libertarian freedom: what if A is breathing under water or living two thousand centuries? For, given that neither $x$ 's breathing under water nor $x$ 's living two thousand centuries are logically contradictory states of affairs, it must exist a possible world $w_{i}$, according to

${ }^{13}$ See Plantinga 1966: 104, Plantinga 1974b: 29. 
TC, where $x$ exists and breathes under water, or a possible world $w_{k}$ where $x$ exists and lives that long. But this fact (if it is a fact indeed) says little about $x$ 's PDO with respect to $\mathrm{A}$ in the actual world.

Hence, the mere existence of such possible worlds is at most a necessary condition for freedom. It seems nonetheless that something more is needed, namely a substantive de re specification of what the class of accessible-to-@ worlds must be like, or else the kind of PDO underpinned by TC will retain a ring of mystery, if not magic indeed. Thus, insofar as TC is not backed by an account of how accessible worlds must behave in order for agents to be free given divine essential omniscience, it is legitimate to suppose that the de re and the de dicto TC-claims are not equivalent and must thereby be kept distinct, on pain of making PDO consistent even with acting differently by matters of sheer chance. And surely the latter is not what Plantinga has in mind when he claims libertarian freedom to be compatible with divine essential omniscience ${ }^{14}$.

\section{References}

- Fischer 1989. John Martin Fischer ed., God, Foreknowledge, and Freedom, Stanford University Press, Stanford 1989.

- Fischer 1993. John Martin Fischer, Recent Work on God and Freedom, "American Philosophical Quarterly" 29, 1993: 91-109.

- Grim 1985. Patrick Grim, Against Omniscience: The Case for Essential Indexicals, "Nous" 9, 1985: 151-158.

- Helm 1988. Paul Helm, Eternal God: A Study of God without Time, Clarendon Press, Oxford 1988.

- Hughes 1995. Gerard Hughes, The Nature of God, Routledge, London New York 1995.

- Kenny 1979. Anthony Kenny, The God of the Philosophers, Clarendon Press, Oxford 1979.

- Leftow 1991. Brian Leftow, Time and Eternity, Cornell University Press, Ithaca London 1991.

- Padgett 1992. Alan Padgett, God, Eternity, and the Nature of Time, Wipf and Stock Publishers, Eugene 1992.

- Pike 1966. Nelson Pike, Divine Omniscience and Voluntary Action, "The Philosophical Review" 74, 1965: 27-46.

\footnotetext{
${ }^{14}$ I wish to thank Edgar Morscher and Tommaso Piazza for their helpful comments and suggestions
} 
- Pike 1970. Nelson Pike, God and Timelessness, Schocken Books, New York 1970

- Plantinga 1966. Alvin Plantinga, Pike and Possible Persons, "Journal of Philosophy" 63, 1966: 104-108.

- Plantinga 1974a. Alvin Plantinga, The Nature of Necessity, Clarendon Press, Oxford 1974.

- Plantinga 1974b. Alvin Plantinga, God, Freedom, and Evil, Harper \& Row, New York 1974.

- Prior 2003. Arthur Prior, The Formalities of Omniscience. In Arthur Prior, Papers on Time and Tense, Per Hasle - Peter hrstrm - Torben Braner - Jack Copeland eds., Oxford University Press, Oxford - New York 2003: 39-58.

- Quinn 1985. Philipp Quinn, Plantinga on Freedom and Foreknowledge. In Peter van Inwagen - James Tomberlin eds., Alvin Plantinga, D. Reidel, Dordrecht 1985: 271-287.

- Stump-Kretzmann 1981. Eleonore Stump - Norman Kretzmann, Eternity, "Journal of Philosophy" 78, 1981: 429-458. 